\title{
A superiorly based, externally pedicled nasolabial flap for the repair of complex nasal tip defects
}

\author{
Selig Krajden MD, Bert Van Brenk MD FRCSC, \\ John L Semple MD FRCSC, Mitchell H Brown MD FRCSC
}

\begin{abstract}
S Krajden, B Van Brenk, JL Semple, MH Brown. A superiorly based, externally pedicled nasolabial flap for the repair of complex nasal tip defects. Can J Plast Surg 2002;10(2):81-84.

The reconstruction of nasal tip defects can often be quite challenging. For small or superficial defects, primary closure, secondary healing or skin grafting are common options. For larger, full thickness defects with exposed cartilage, local or distant flaps are usually required. An experience using a superiorly based, externally pedicled nasolabial flap for full thickness nasal tip defects in six patients is described. The reconstruction is performed in three stages, allowing for aggressive thinning and debulking of the flap at the time of final insetting. The flap has good excursion with a wide arc of rotation, allowing it to be used in a variety of complex nasal tip defects. Patient satisfaction with the eventual outcome has been excellent.
\end{abstract}

Key Words: Nasal reconstruction; Nasolabial flap

\section{Lambeau naso-labial à pédicule externe, supérieur pour les reconstructions complexes de la pointe du nez}

RÉSUMÉ : La chirurgie de reconstruction de la pointe du nez s'avère souvent fort délicate. Pour les pertes de substance superficielles ou de petite taille, la suture primitive, la cicatrisation secondaire ou les greffes de peau sont pratique courante. Par contre, pour les pertes étendues ou totales de substance, avec exposition du cartilage, il faut généralement recourir aux lambeaux prélevés à proximité ou à distance. Voici la description d'une technique expérimentale pratiquée sur six patients et consistant en la pose d'un lambeau naso-labial à pédicule externe, supérieur pour perte totale de substance. La reconstruction se fait en trois temps, ce qui permet un amincissement et une réduction marqués du lambeau au moment de la mise en place finale. Le lambeau est facile à déplacer et présente un grand arc de rotation; il peut donc servir à un large éventail de reconstructions complexes de la pointe du nez. Les patients se sont montrés très satisfaits des résultats.
$\mathrm{T}$ he reconstruction of a nasal tip defect can present a difficult technical challenge for any surgeon. The ultimate goal of nasal tip reconstruction must incorporate closure of the original defect while restoring the cosmetic appearance of the nose, and minimizing distortion of surrounding struc- tures such as the alar rim and nasofacial groove. A variety of techniques have been described to achieve this goal; these include primary closure or secondary healing for smaller defects and local flaps, and full thickness skin grafts or composite grafts for larger nasal tip defects $(1-4)$.

Division of Plastic Surgery, Department of Surgery, University of Toronto, Toronto, Ontario

Correspondence: Dr Mitchell Brown, Sunnybrook and Women's College Health Sciences Centre, Women's College Campus,

76 Grenville Street, Suite 650, Toronto, Ontario M5S 1B2. Telephone 416-323-6336, fax 416-323-6325, e-mail mhbrown33@aol.com 

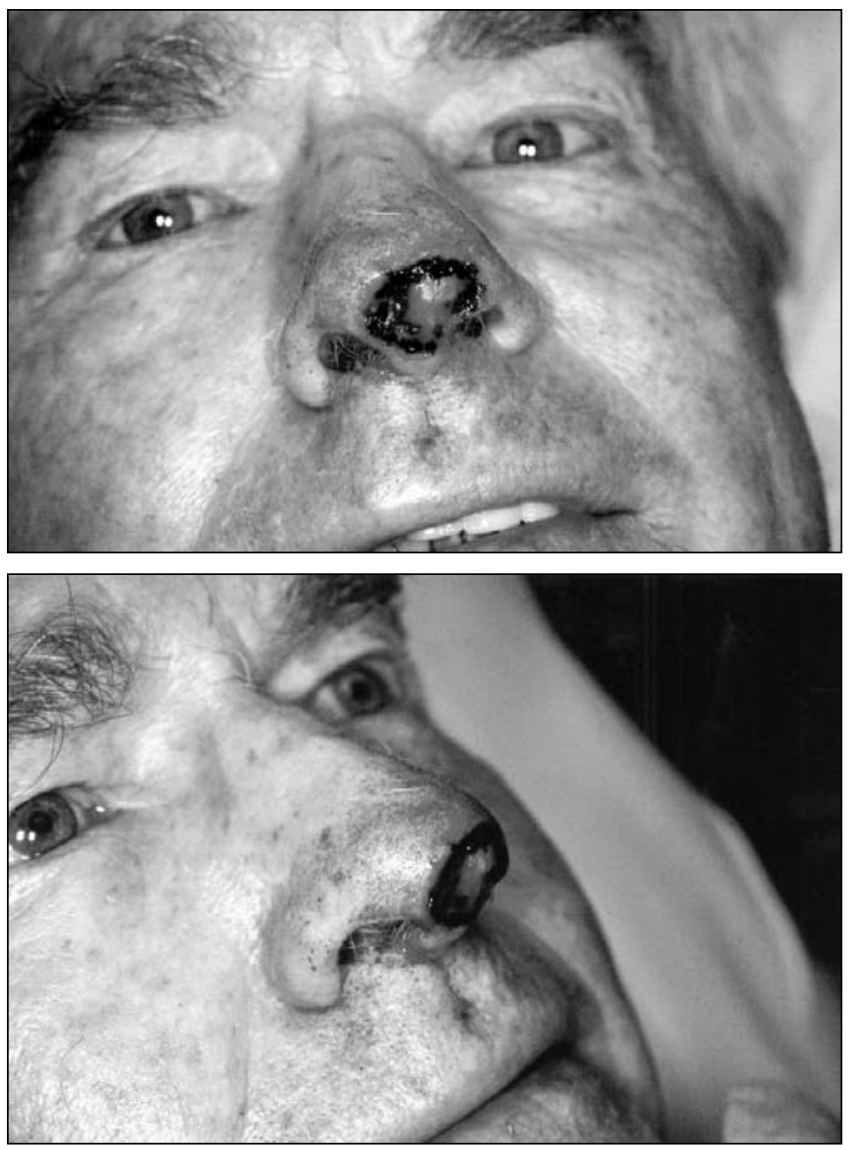

Figure 1) Fifty-five year-old male patient after Mohs micrographic excision of a recurrent basal cell carcinoma of the nasal tip

Nasolabial flaps have long been used for nasal tip reconstruction, with varying success. Problems such as pin cushioning and trap door contracture have prompted surgeons to develop further and refine their approaches to this complex reconstruction. When a single stage nasolabial flap is used, there is often a problem with bulkiness throughout the length of the flap and with a defect at the base of the flap (5). However, meticulous planning and execution of a refinement of the nasolabial flap can lead to excellent results. We would like to present our experience using the staged, superiorly based, externally pedicled nasolabial flap (EPNLF) for nasal tip reconstruction in six patients.

\section{PATIENTS AND METHODS}

Six patients undergoing Mohs micrographic surgical excision of a basal cell carcinoma (BCC) were evaluated. Pathologically, four of these were sclerosing BCCs, and the other two were recurrent, nodular BCCs. The average age of these patients was 54.5 years; five of the patients were male and one was female. All of the resulting defects postBCC resection involved the nasal tip and exposed the underlying cartilage; as well, one of the defects involved the nasal dorsum. Only one of the patients had prior radiation to the area. In five of the patients, a unilateral flap was used; a bilateral flap was necessary for complete coverage in the other patient.

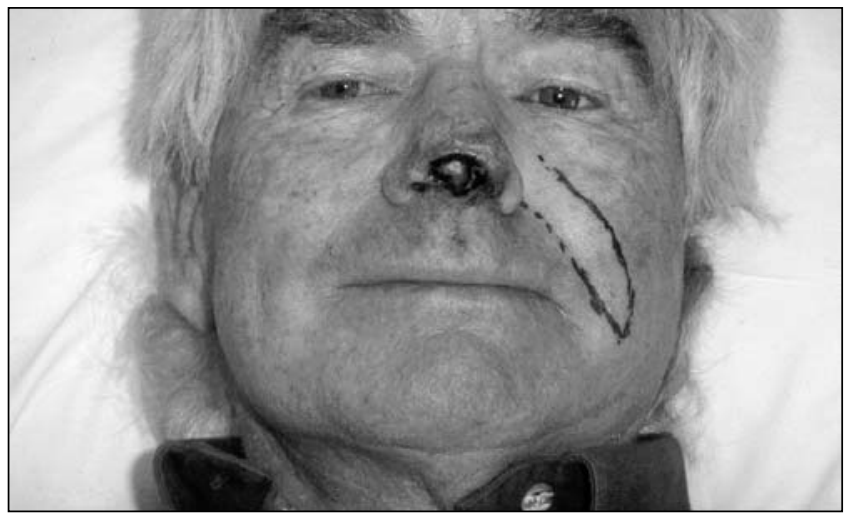

Figure 2) Outline of a superiorly based, externally pedicled nasolabial flap for the repair of a complex nasal tip defect

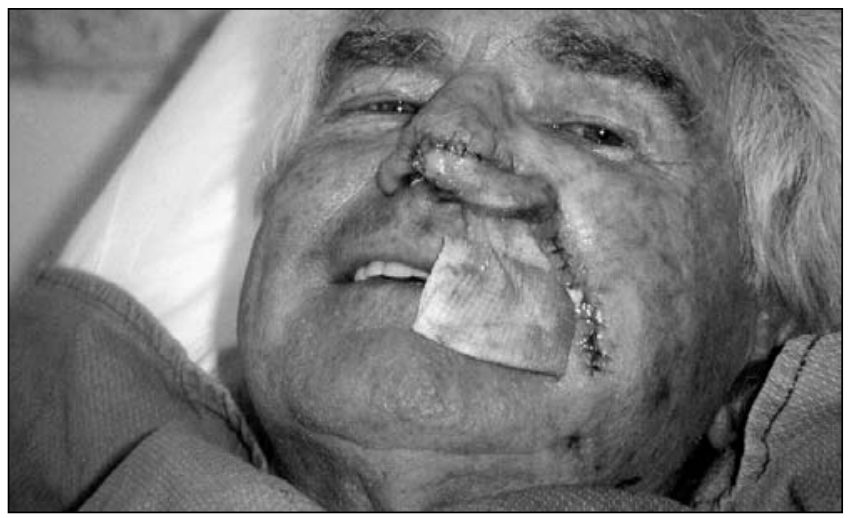

Figure 3) Elevated and transposed nasolabial flap, and closed donor site

Under local anesthesia (lidocaine with 1:200,000 adrenaline), the lesion on the nasal tip was excised using Mohs micrographic surgery to obtain clear surgical margins. A superiorly based nasolabial flap was marked out to close the defect. The width of the flap was marked to ensure adequate closure and to avoid distortion of the patients' upper lip after closure. The length was measured to allow for an externalized pedicle under minimal tension. The flap was raised in the subcutaneous plane, with care to avoid the angular artery at the base of the flap. The distal end of the flap was then sutured into the defect. The donor defect was closed primarily in two layers, ensuring that the closure did not compromise the base of the flap. In addition, the undersurface of the flap was dressed to prevent drying. At three weeks, the base was divided, and the nasolabial fold donor site was revised and closed. The flap that had been sutured into the defect was left completely undisturbed. The final debulking and insetting of the flap was completed one week after division of the base. Waiting this additional week after division of the pedicle acted like a delay procedure in that it allowed for aggressive thinning and debulking of the flap at the time of insetting (Figures 1 to 6).

\section{RESULTS}

Six patients underwent nasal tip reconstruction using the superiorly based EPNLF. All of the patients underwent the 


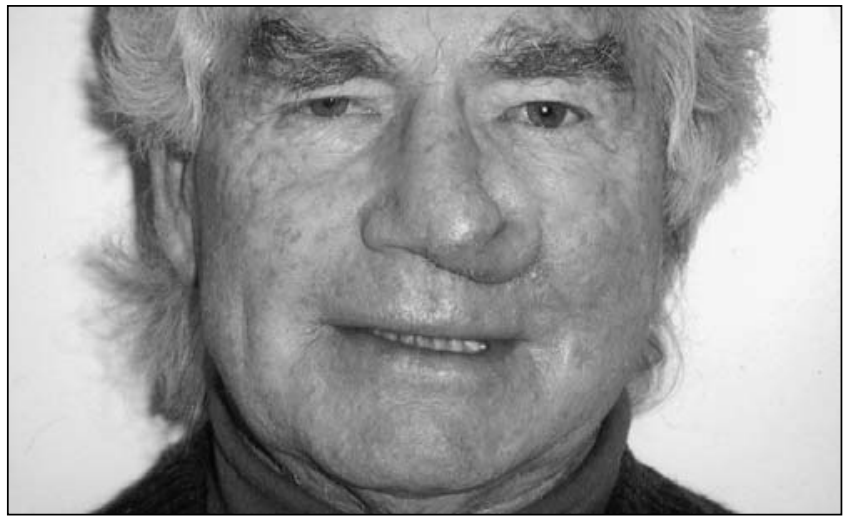

Figure 4) Appearance of the nasolabial flap after three weeks

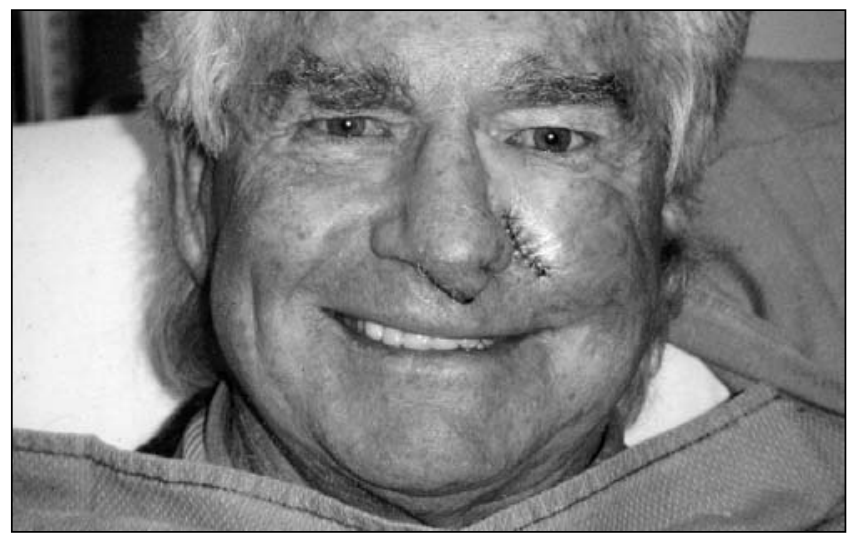

Figure 5) Appearance of the nasolabial flap after division of the flap base and tailoring of the donor site

three procedures as described above. One patient had a fourth procedure to revise the flap further six months after completion of the initial reconstruction. There were no cases that involved complete or partial flap loss. There was one case of persistent bleeding from the raw surface, in which it was necessary to take down the flap to achieve hemostasis. Overall, patient satisfaction with the staging involved in this procedure and the final aesthetic results have been excellent. One patient (male) has undergone electrolysis to remove several persistent hairs on the nasal tip.

\section{DISCUSSION}

The nasolabial flap has been used for nasal reconstruction since the mid-19th century. Since then, numerous modifications to this flap have been described for reconstruction of a variety of nasal defects. These have included nasal tip, alar and columellar defects, with or without the requirement of nasal lining. Recent modifications have attempted to prevent the cosmetic deformities (including pin cushioning and loss of the nasofacial groove) that have been reported using this technique (6-8). This has resulted in renewed interest in including the nasolabial flap in the armamentarium of nasal tip reconstruction.

The superiorly based nasolabial flap is a random skin flap, with branches from the angular, infraorbital, trans-
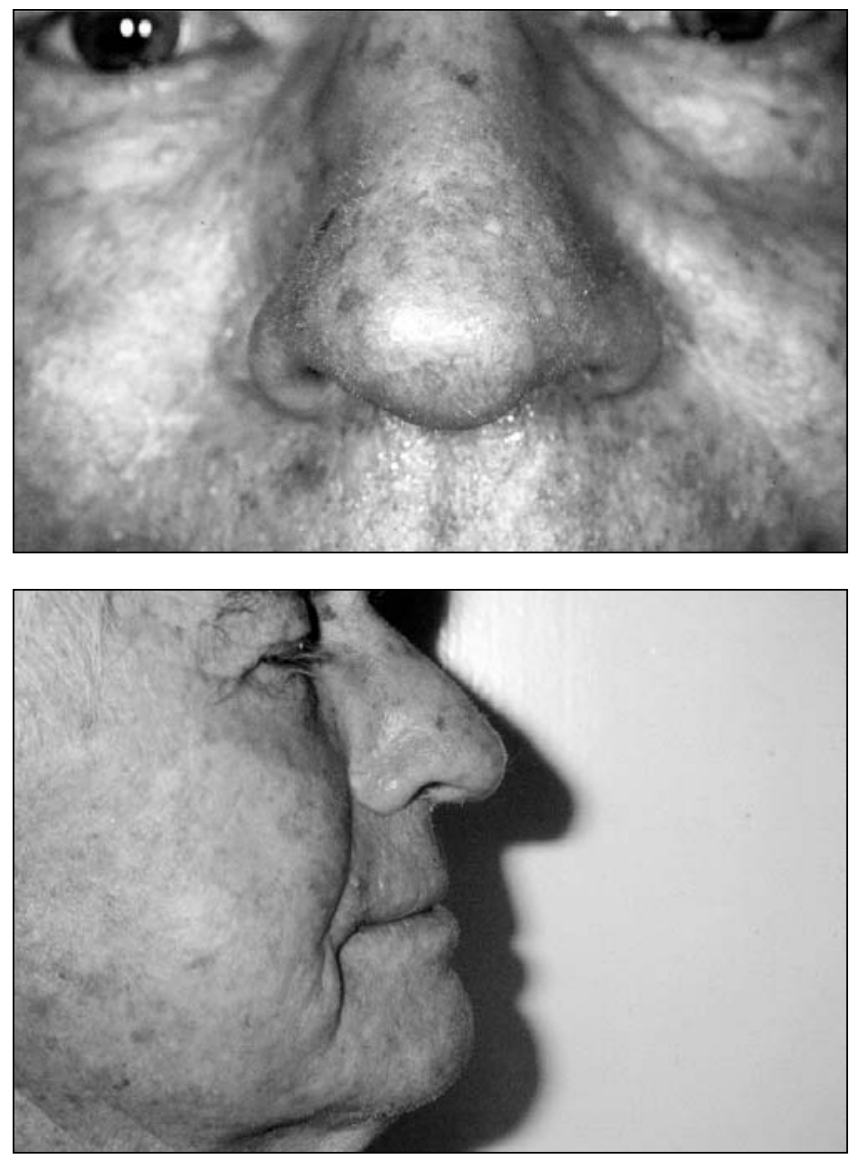

Figure 6) Appearance of the nasolabial flap six months postoperatively

verse facial and infratrochlear arteries contributing to the subdermal plexus $(9,10)$. The flap is rotated on a pivot point just superior to the lateral incision. The size of the flap is usually limited by the ability to close the donor site primarily. In patients with redundant tissue near the nasolabial fold, a flap width of up to $5.0 \mathrm{~cm}$ has been described, although the width should usually be kept to less than $3.0 \mathrm{~cm}$. A flap length of up to 10 to $12 \mathrm{~cm}$ can be taken safely. If the flap length required is greater than $12 \mathrm{~cm}$, a delay procedure should be seriously considered. A generally accepted ratio of width to length is approximately $3: 1$ to $4: 1(1)$.

We believe that the nasolabial flap has several advantages over other techniques used for closure of nasal tip defects. The donor site morbidity is fairly minimal, because the incision is placed in the nasolabial fold, and the surrounding nasal skin is not violated as part of the flap. The length of the flap available is usually sufficient to reach the defect on the nasal tip, including those that cross the midline. However, in our series, bilateral flaps were required to close a particularly large defect in one patient. A nasolabial flap can also be used for the reconstruction of full thickness defects, in which both skin coverage and nasal lining are required. If the full thickness defect of the nasal tip extends to include the alar rim, the nasolabial flap can be 
folded on itself to provide nasal lining and reconstruct the alar rim. A modification of folding the nasolabial flap on itself has been described for full thickness defects of the tip and ala with an intact alar rim. This provides both lining and skin coverage without sacrificing the patient's own alar rim in an ala and alar rim cosmetic subunit reconstruction $(11,12)$. Another option for full thickness defects involves using the nasolabial flap in conjunction with a skin or mucosal graft.

Despite it's advantages, the nasolabial flap does have some drawbacks. Reconstruction using the flap, as described in this article, is a multistaged procedure requiring regular dressing changes and return visits, which may be inconvenient for the patient. As well, secondary revisions to debulk the flap are not uncommon, especially in men, in whom the flap may be thicker than the surrounding nasal skin. A further disadvantage in men is that the distal cheek skin is hairbearing and may bring hairbearing tissue onto the nose with the reconstruction. Careful planning and surgical technique, including insetting and meticulous defatting of the flap, can prevent a poor cosmetic outcome.

Final flap insetting was delayed until the third patient visit in our series; this was approximately one week after division of the flap and four weeks after the initial procedure. This minimizes trauma to new vessel ingrowth into the distal portion of the flap at the time of division of the flap and thereby reduces the chances of complete or partial flap loss. At the third stage, debulking and final insetting of the flap can be done more aggressively and with a higher safety margin.

\section{CONCLUSIONS}

This paper describes the use of the superiorly based EPNLF for the reconstruction of complex nasal tip defects in six patients. Although the cases in the present series all had lesions resulting from $\mathrm{BCC}$ resection, the same technique could be used for defects resulting from trauma, infections or other skin tumours. This flap provides an excellent colour and contour match, good blood supply and a wide arc of excursion to cover most nasal tip region defects. The main disadvantage is the requirement for a staged procedure. However, with proper patient education, this inconvenience is easily overshadowed by the quality of the eventual result.

\section{REFERENCES}

1. Strauch B, Vasconez LO, Hall-Findlay EJ. Grabb's Encyclopedia of Flaps: Head and Neck, 2nd edn. Philadelphia: Lippincott, Williams and Wilkins, 1998:156-61.

2. Gloster HM Jr. The use of full-thickness skin grafts to repair nonperforating nasal defects. J Am Acad Dermatol 2000;42:1041-50.

3. Wheatley MJ, Smith JK, Cohen IA. A new flap for nasal tip reconstruction. Plast Reconstr Surg 1997;99:220-4.

4. Snow SN. Rotation flaps to reconstruct nasal tip defects following Mohs surgery. Dermatol Surg 1997;23:916-9.

5. Zitelli JA. The nasolabial flap as a single-stage procedure. Arch Dermatol 1990;126:1445-8.

6. Pharis DB, Papadopoulos DJ. Superiorly based nasolabial interpolation flap for repair of complex nasal defects. Dermatol Surg 2000;26:19-24

7. Hosaka Y, Tsukagoshi T, Sasaki E, Yokoyama S. The use of otherwise redundant skin to provide nasal lining in the reconstruction of full-thickness alar defects by nasolabial flap repair. Br J Plast Surg 1999;52:29-32.

8. Uchinuma E, Matsui K, Shimakura Y, Murashita K, Shioya N. Evaluation of the median forehead flap and the nasolabial flap in nasal reconstruction. Aesthetic Plast Surg 1997;21:86-9.

9. Field LM. Design concepts for the nasolabial flap. Plast Reconstr Surg 1983;7:283-5.

10. Haneke E. Surgical treatment of defects on the tip of the nose. Dermatol Surg 1998;24:711-7.

11. Yotsuyanagi T, Yamashita K, Urushidate S, Yokoi K, Sawada Y. Nasal reconstruction based on aesthetic subunits in Orientals. Plast Reconstr Surg 2000;106:36-46.

12. Shumrick KA, Campbell A, Becker FF, Papel ID. Modification of the subunit principle for reconstrucion of nasal tip and dorsum defects. Arch Facial Plast Surg 1999;1:9-15. 